\title{
A Contrastive Study on Cultural Connotations of "Red" in English and “红” in Chinese and Their Translation Strategies
}

\author{
Jia Nan \\ Changchun University of Finance and Economics Changchun, China \\ 1493116216@qq.com
}

Keywords: red, cultural differences, translation strategies.

\begin{abstract}
Color as one of the important means of human understanding of the world, has a certain physical properties and rich cultural characteristics. The paper aims to analyze the differences of the color of "red" in English and in Chinese and their translation strategies. First, it gives the definition of color and cultural connotations. Then, it discusses the cultural connotation of "red" in English and “红” in Chinese respectively. Third, it analyses the causes of different cultural connotation between "red" in English and "红" in Chinese in several aspects, including historical backgrounds, culture psychology, and mode of thinking. Last, this paper points out the translation strategies of "red" in English and "红" in Chinese from literal translation, replacement with other color words and free translation.
\end{abstract}

\section{Introduction}

From the English learning, we can find that the culture of each nation has its own unique characteristics. The color terms are an essential part of the national culture and language, which is an important area of human understanding of the world (Xiao Qianpei, 2009). Sometimes we cannot understand some color terms, because they are deeply rooted in its own culture. Color terms have a strong national culture characters. Each nation has its own color view. In different national culture, the same color expresses different cultural psychology, cause different associations, and has different cultural connotations. So, to understand and master the similarities and differences of color terms in different languages plays an important role in promoting the cross culture smoothly.

The biggest difficulty of translation is the differences of two kinds of culture. Thus, it is crucial to deal with cultural differences in translation of the color "red". This paper takes the "red"as the study object to contrast connotation of color red in English and in Chinese and their translation strategies to convey the deeper meaning of culture more accurately. Throughout the study, this paper can help readers reduce embarrassment in communication and understanding.

\section{Literature References}

Language is the carrier of culture. Different languages can reflect the cultural connotation in different countries and areas. Color terms as an important part of language play a decisive role in disseminating culture. At the same time, color terms, as a special kind of culture loaded words, are closely related to human life. In English language and Chinese language, there are large number of expression about color, expressing specific cultural connotation. Since English and Chinese belong to two different cultural groups, the same color association is different, sometimes even completely contrary. So, it is necessary to grasp the relationship between color terms and culture to avoid unnecessary embarrassment.

\subsection{Previous Studies on Color Terms at Abroad.}

Culture is a very important factor in the translation for color words. There are many studies at home and abroad. They study the phenomena in different ways and from different aspects. In west countries, color terms are popular in fields like philosophy, physics, psychology, art and so on. The oldest theory in color terms' history is Aristotle's Black and White Theory, in which color is made up of hue, luminosity and saturation. At that period, all colors were thought as different degrees of 
mix of white and black. Black and White Theory was ended by Newton who saw seven colors of the sunlight through prism. Other theories appeared at the same time, such as Sapir-Whorf Hypothesis and Cognitive Linguistics. In spite of the relationship between these theories, they all admitted color terms' important position in English.

\subsection{Previous Studies on Color Terms at Home.}

With the development of American linguistics, the study of color words in the first half of twentieth century mostly takes as the background. More typical example is H.C.Conklin and H.A.Gleasoii, who put the color words compared to the color of several other languages. The domestic research started relatively late on color words, mainly referring to the research achievements in the west. But in recent years, with the popularity of Chinese in the world, more and more scholars have also done a lot of discussion and study on Chinese color words. Wu Tieping's Theory of Color Words and Fuzzy Nature is a fuzzy semantic research on color words. And Zhang Wangxi's Lenovo Color at The Beginning is a research on associative meaning of color words. What's more, Liu Yunquan's Color Words Constitute The Antithesis Way and Its Expression Function outlines a framework for the development of Chinese basic color words and so on (Huang Youqing, 2006).

\section{Cultural Connotations of "Red" in English}

Cultural connotations of "red" in English have positive meaning and negative meaning. The positive use of "red" in English is very much limited. Instead, it is often used in a derogative sense, connected with "blood", "danger" and "violence" in the minds of native speakers.

\subsection{Positive Cultural Connotations of "Red" in English.}

Red linked with happy festive things in English culture, such as the "red" in the "red-letter day" with the meaning of holidays like Christmas and other special days. Such days are printed in red on calendars, rather than in black for ordinary days. Another example is to paint the town red-meaning to celebrate wildly, to go out to drink and have a good time. "Red Nose Day" is a day on which an appeal is made for donations for research into sudden infant death syndrome, marked by the distribution of plastic red noses to donors. the "roll the red carpet for somebody" which is the mean of “隆重欢迎某人” has the festive meaning. In English culture, people cover with red carpet which symbolizes the solemn and grand when they welcome ceremony in marriage or heads. For example, "red carpet treatment" that is, "the kind of courtesy of deference shown to person of high station" is decided by “red carpet”to express “隆重, 高贵”. Westerners send red roses to a lover, and red tomatoes is known as "love apple" (Fu Junfang, 2005:50).

\subsection{Negative Cultural Connotations of "Red" in English.}

In western culture, red is a very strong negative word, which is often connected with danger, terror and bloody, such as "red revenge" means “血腥报复”, and “red battle” is the meaning of “血战”. “Red hot political campaign” is called “残杀和暴力统治”, and “have red hands”, “red ruin”, “redhanded” respectively means “杀人犯”, “火灾” and “当场抓住” (Venuti, 2001). “Red” in English is often said of communism, a symbol of revolution. However, "go into the red" 或 “ in the red" means “赤字”, and “ red balance” is the meaning of “赤字差额”. “in red ink" is not the meaning of “红墨 水” but “宂空”. "Red A word” is a kind of adultery logo and a symbol of shame. In Hawthorne's novel The Scarlet Letter, Hester Prynne, an adultery woman who made "seventh ring" is punished by Garr educational punishment, must wear a sign of adultery red "A" word in public. And "a red flag" in English expresses “危险信号旗”.

\section{Cultural Connotations of "红" in Chinese}

Different from the cultural connotations of "red" in English, the color word "红" in Chinese is often regarded as the symbol of celebration, luck, victory, loyal and welcome. Obviously, the positive meaning of “红” in Chinese outweighs the negative meaning. 


\subsection{Positive Cultural Connotations of "红" in Chinese.}

The meaning of color terms "red" and “红” are not same in many ways. In China, first, "红” is the symbol of “communism”. Such as “五星红旗”, the Chinese national flag, is red which means being stained red by the blood of the revolutionaries and martyrs, and “红领巾” is a corner of it. Second, “红” has the meaning of “红军”, “红色政权” and “红色根据地”, indicating the revolution. “红色路 线” is the meaning of "the revolutionary policy". Third, in the Cultural Revolution, there are a lot of “红”-related expressions which are used politically, taking the followings as example: “红色长城” means “ the people's Liberation Army”, “红太阳” is the meaning of “Chairman Mao”. “红色江山” is accord with "the socialist country governed by the proletariat" (Xiao Peiqian, 2009).

\subsection{Negative Cultural Connotations of "红" in Chinese.}

Red is the symbol of anger. In China, “脸红脖子粗”, “面红耳赤” are used to symbolize anger. “红” in Chinese is often used to express one's envy just as it is in the expression “眼红”. In accounting terminology, red is an unpopular word. Such as “赤字” in China. “Red light district” is the place where people should not go. And the name of a death row is written in red. That is to say, it is the supreme power deprive him of his life, irreversibly. Writing with the red pen is not allowed because the red words mean the end of relationship. Because of the red blood, red commonly is used to represent the disaster and violence. For example, “赤地千里” in Chinese describes a large number of land desolate scene caused by natural disaster or war . “赤字”, “赔了血本” and so on in Chinese have the meaning of "running a business in the red", "red figure" and "red ink". People have emotional responses in front of objective things. In Chinese culture, red can be extended to express a person's emotional state such as excitement, shame, and offence. For example, someone often shows "red face" when he is angry, and he will feel shy when he does something wrong. What's more, red is also the symbol of criminals who are also known as “赫衣”, because the person who was sentenced to death in China's ancient times usually worn in red. In the white terror era, people have the psychological feeling of "red" with “dangerous” and “ prison”. “戴上红帽子” means being in jail. Until today, the person who is sentenced to death wears a brand with a big red ink fork. When he is announced to death, there is a red tick on his name (Ke Yan, 2009).

\section{Translation Strategies of "Red" in English and "红" in Chinese}

The famous linguist Wang Zuoliang of our country once says, "He (translator) deals with the individual words, but he faces two cultures" (Jin Yu, 2011: 45). In other words, the greatest difficulty in translation is the cultural differences. Thus, interlingual translation is not only the linguistic symbol and its meaning, but also is the mutual communication and transplantation of two different cultures. Translation, to a certain extent, becomes a kind of cultural exchange. Influenced by the cultural differences between the two countries, the color word "red" and "红" are not the same in the association and the symbolic significance caused by visual and mental, so special attention should be paid to the differences in translation.

\subsection{Literal Translation.}

"Catford argues that literal translation takes word-for-word translation as its starting point, although because of the necessity of conforming to TL grammar, the final TT may also display groupgroup or clause-clause equivalence" (Catford, 1965: 25). On the surface, the literal translation refers to not change the original words and the original sentence. Strictly speaking, the aim of literal translation is to retain the original emotion and style. In other words, it preserves its cultural meaning without changing the original form of language maximally. Although the cultural connotation and social identity are different between Chinese and English, the international communication becomes increasingly frequent in the long development process of history to promote the integration and penetration of the two cultures, so that the implied meaning of the two countries" color word "red" in the context becomes the same. 


\subsection{Replacement with Other Color Words.}

Replacement means that the cultural connotation reflected by the color words in the source language is replaced by using another color words in the target language to express. That is to say, the color "red" of source language is translated into other color words in the target language

\subsection{Free Translation.}

The so-called "free translation" is to translate the original meaning without the pursuit of the original form of language. Because of the differences existed in the language expression, the way of thinking and cultural background, the symbolic meaning of the various colors in English and in Chinese are different. Using literal translation may not be faithful to the original, and it is not accepted by the readers. We'd better develop a proper sentence structure by using mode of thinking and the habit of expression in the target language.

\section{Conclusion}

The above discussion leads to the conclusion that under the influences of natural environments, historical backgrounds and religious beliefs of eastern and western world, English and Chinese color words have their cultural connotations respectively. As the carrier of culture, language absorbs different cultures of different nations. Color words, as an important part of language, express special characteristics and customs. Each color has its way of expression in different nations. Red, as a basic color, is commonly used in daily life and carried vivid meaning both in English and in Chinese. Therefore, to study red is significant for us to comprehend and grasp the accurate meaning of color in English and Chinese culture.

\section{References}

[1]. Catford. J.C. A Linguistic Theory of Translation [M]. Cambridge: Oxford University Press, 1965.

[2]. Venuti. L. Strategies of Translation: A Rout Ledge Encyclopedia of Translation Studies [M].

[3]. New York: Rutledge, 2001.

[4]. Fu Junfang. A Contrastive Study of English and Chinese "Red" Vocabulary[J]. Journal of Xi'an Foreign Language College, 2005, (3): 50-55.

[5]. Huang Youqing.The Cultural Meaning of Chinese Color Words [D].Tianjin: Tianjin Normal University, 2006.

[6]. Jin Yu. On the Cultural Connotation of Chinese and English Color Words "Red" and "red" and Their Translation Strategies[J]. Foreign Languages Department of Zhejiang Wanli College, 2011, (6): 45-46.

[7]. Ke Yan. The Similarities and Differences of Red Symbolic Meaning in Chinese and Western Culture[J]. Foreign Language Teaching Department of Taishan College,2009,(13): 31-34.

[8]. Xiao Peiqian. On the Similarities and Differences of Chinese and English Cultural Connotation from Red[J]. Jiangxi Blue Sky College, 2009, (5): 46-47. 